\title{
ASPECTOS SOCIOECONÓMICOS DE UN GRUPO PRIVI- LEGIADO DEL ANTIGUO RÉGIMEN. LOS OBISPOS DE CÁDIZ (1556-1833)
}

\author{
Maximiliano Barrio Gozalo \\ Universidad de Valladolid
}

\section{$\underline{\text { RESUMEN }}$}

En las páginas siguientes se estudian los aspectos socioeconómicos de los obispos que rigen la diócesis de Cádiz en el largo periodo de 1556-1833, pues el poder socio-religioso que detentan les convierte en una de las elites más importe del obispado. Después de examinar las fuentes que utilizo en el estudio, analizo algunos aspectos sociológicos de los obispos (edad de nombramiento, origen regional y social, formación y experiencia profesional) y las rentas que cobra como titular del obispado, contando sus gastos, cargas y pensiones para evaluar de forma aproximada el importe de la renta que queda a la libre disposición del obispo.

Palabras clave: Antiguo Régimen, Cádiz, obispos, aspectos sociales, rentas, pensiones.

\section{ABSTRACT}

The purpose of the next pages is to study the economic and social aspects related to the Bishops, whom rule the Diocese of Cadiz during a long timely period, from 1536 to 1833 . Due to the social and religious power they have, become one of the elite of the Bishopric. After examining my work sources, 1 ponder some sociological aspects of the Bishops (their appointment age, regional and social-caste origin, training and involved practice), and the revenues they obtain as the head of the Bishopric, their expenses, taxes and pensions to value approximately the quantity of revenues which is entirely managed by the Bishop.

Keywords: Ancien Régime, Cadiz, Bishops, social aspects, revenues, pensions. 
Cada vez son más frecuentes los estudios que se interesan por los diferentes grupos sociales, y entre ellos del clero', de forma que ya no es un desconocido como afirmaba Fernández Díaz en $1990^{2}$. Es verdad que falta mucho por hacer, pero hoy ya es frecuente ver estudios sobre los integrantes del colectivo eclesiástico desde una perspectiva social, que ofrecen información sobre su naturaleza familiar, cultural, religiosa, política y económica, y permiten trazar un biografia colectiva que nos aproxime a una sociología retrospectiva de este grupo social.

En consecuencia, las siguientes páginas van a tratar de analizar los aspectos socioeconómicos de los obispos que rigen la diócesis gaditana desde el inicio del reinado de Felipe II (1556) hasta la muerte de Fernando VII (1833), puesto que el poder económico, social, religioso, cultural y, a veces, también político que detentan les convierte en una de las elites más poderosas del obispado.

\section{Las fuentes}

Las fuentes que posibilitan el estudio socioeconómico de los obispos de Cádiz en este periodo se encuentran fundamentalmente en los archivos del Vaticano, Simancas e Histórico Nacional de Madrid ${ }^{3}$. Las distintas series del fondo consistorial del Archivo Vaticano, sobre todo las de Procesos consistoriales, Acta camerarii y Acta miscelánea ofrecen información sobre los aspectos sociológicos de los prelados.

Los procesos consistoriales son una de las fuentes más ricas para estudiar la sociología de los obispos y, a partir del concilio de Trento, se fue precisando cada vez más la normativa sobre la manera de instruirlos ${ }^{4}$. E1 proceso consta de dos interrogatorios sobre los que debian declarar tres testigos "en serie y por extenso,

\footnotetext{
'Entre los estudios publicados por Barrio Gozalo sobre la jerarquía eclesiástica se pueden citar los siguientes: "Perfil socioeconómico de una elite de poder:, V: Los abispos de Andalucia, 1600-1840", en Anthologica Annua, 34 (1987), pp. 11-188; "La economia de los obispos en la España del Antiguo Régimen, 1556-1834", en Fra Spazio e Tempo. Studi in onore di Luigi De Rosa, Napoli 1995, vol, I, pp. 33-57; Los obispos de Castilla y León durante el Antiguo Régimen. Estudio socioeconómico, Valladolid 2000; etc.

"La clerecía catalana en el Setecientos", en Església $i$ societat a la Catalunya dei s. XVIII, Cervera 1990, vol. 1, pp. 23-118.

' Las abreviaturas que se utilizan son las siguientes: $\mathrm{AGS}=$ Archivo General de Simancas; $\mathrm{AHN}=$ Archivo Histórico Nacional, Madrid; ASV = Archivo Secreto Vaticano; $\mathrm{AC}=$ Acta Camerarii; $\mathrm{AV}=$ Acta Vicecancellarii; $\mathrm{AM}=$ Acta Miscelánea; $\mathrm{PC}=$ Processus Consistoriales; $\mathrm{PD}=$ Processus Datariae; AEESS = Archivo de la Embajada de España ante la Santa Sede, depositado actualniente en el Archivo del Ministerio de Asuntos Exteriores de Madrid; y BEESS = Biblioteca de la Embajada de Espaĩa ante la Santa Sede.

"Información sobre los procesos en RITZLER, R., "Procesos informativos de los obispos de España y sus dominios en el Archivo Vaticano", en Anthologica Annua, 4 (1956), pp. 466-474.
} 
sin que se admitan las solas afirmaciones o negaciones en forma precisa y lacónica". El primero, que es el que ahora nos interesa, consta de trece preguntas y versa sobre las cualidades personales del electo: edad, padres, lugar de nacimiento, grados académicos, cargos desempeñados, costumbres, etc 5 .

La serie de Acta camerarii está constituida por actas consistoriales de carácter oficial, es decir, notas oficiales sobre los consistorios públicos y secretos en los que se hacía la presentación y nombramiento del electo para una determinada diócesis. A pesar de su brevedad, estas notas aportan interesante datos históricos. Primero, indican la fecha exacta de la confirmación del obispo y, por tanto, permiten saber con precisión el día de su preconización; y segundo, informan del cardenal protector o relator que hace la propuesta en el consistorio, la edad y profesión del electo, diócesis a que pertenece, cargo que desempeña, grados académicos, nombre del obispo anterior, causa de la vacante, monto de las rentas y pensiones que se le imponen. Las mismas características reúnen las Acta vicecancellarii ${ }^{6}$.

La serie de Acta miscelánea es una colección de documentos consistoriales, pero sin carácter oficial alguno ${ }^{7}$. Generalmente son extractos y copias de las Acta camerarii y vicecancellarii hechos con diversos fines.

También hay que hacer mención a las consultas de la Cámara de Castilla relativas a la presentación de los obispos de Cádiz, que en su mayoría se conservan en el Archivo Histórico Nacional, pues ponen de relieve el criterio que las informaba y normalmente ofrecen un breve curriculum vitae de los propuestos, aparte de revelar la importancia que se concedía al factor económico en las provisiones.

Por último hay que hacer alusión a los volúmenes de la Hierarchia Católica, que toma la mayor parte de sus datos del citado fondo consistorial del Archivo

\footnotetext{
'Los procesos sobre obispos de Cádjz se encuentran en ASV, Arch. Concist., PC, vols. 17, 32, 38, 40, $54,60,76,79,85,90,104,117,173,183,192,204,211,216$ y 223; y en Ibídem, Dataria Ap., PD, vol. 51 .

${ }^{5}$ Ibidem, AC, vols. 7, 13, 17, 18, 19, 21, 22, 23, 24, 26, 30, 38, 39, 40, 49, 51, 52 y 54; y en Ibídem, AV, vols. 15 y 16 .

Ibídem, AM, vols. 19,97 y 98 .

${ }^{8}$ AHN, Consejos, legs. 15188-15531: Consultas de la cámara de Castilla sobre el nombramiento de obispos. Años 1570-1834. En AGS, Patronato Eclesiástico, legs. 6 y 137, también hay algunas de la segunda mitad del siglo XVI.

${ }^{9}$ Hierachia Catholica. Medi et Recentioris Aevi, III (1503-1592), Monasterii 1923; IV (1592-1667), Monasterii 1935; V (1667-1730); Patavii 1952; VI (I730-1799), Patavii 1958; y VII (1800-1846), Patavii 1968
} 
Vaticano, a los episcopologios y a los estudios de ámbito local y diocesano ${ }^{10}$, así como a la documentación que se conserva en los archivos diocesano y catedral de Cádiz. En las páginas siguientes, sin embargo, me atendré de forma prioritaria a los datos que aporta la documentación vaticana.

La documentación que voy a utilizar para realizar una evaluación aproximativa de la renta de la mesa episcopal gaditana son las relaciones de valores de la mitra enviadas a la secretaria del real patronato" y los datos que aparecen en los procesos consistoriales y en actas del consistorio, aunque esta documentación presenta algunos problemas que se deben aclarar.

Las relaciones de valores remitidas a la secretaría del real patronato abarcan la segunda mitad del siglo XVI y primeros años del XVII, el fondo de Simancas, y desde 1634 hasta 1825 el fondo de Madrid. Cuando moría un obispo, renunciaba o promocionaba a otra mitra, la secretaría del real patronato escribía al cabildo catedral de Cádiz, sede vacante, pidiendo relación detallada de las rentas de la mitra en el trienio o en el quinquenio anterior ${ }^{12}$, con el fin de cargar al nuevamente provisto las pensiones que cupieran en la tercera o cuarta parte de la renta líquida y deducir la cuantía de la mesada que el electo debía abonar.

El cabildo catedral de Cádiz o el contador del obispo elaboraba las cuentas, analizando año por año, y las remitía a la secretaría del real patronato, donde eran supervisadas por la contaduría de hacienda, que las daba por buenas o las ponía reparos a los que debía dar satisfacción el autor de las mismas. Estas relaciones son muy prácticas para nuestro objetivo, pues algunas indican, junto con la cuantía de los frutos, los precios a que se vendieron y su importe global. Sin embargo, presentan el gran inconveniente de que en vez de valorar los granos al precio de venta lo hacen al de la tasa antigua o uno más bajo, como luego veremos. Esta práctica, seguida de forma generalizada por todas las mitras, también se utiliza en Cádiz hasta mediados del siglo XVIII y ello hace que los valores que se indican hasta la segunda parte del setecientos estén infravalorados.

Los datos que se encuentran en las series de procesos consistoriales y actas del consistorio también precisan una explicación. En el proceso informativo que se hacía al electo que era presentado para Cádiz se realizaba interrogatorio sobre el estado de la iglesia catedral y el obispado, demandando a los testigos en la

\footnotetext{
${ }^{10}$ Entre ellos cabe destacar los de ANTÓN SOLE, P., La iglesia gaditana en el siglo XVIII, Cădiz 1994; y MORGADO GARCIA, A., Iglesia Y sociedad en el Cádiz del siglo XVIII, Cádiz 1989, aunque sólo ofrecen información sobre el setecientos.

"Se encuentran en AGS, Patronato Eclesiástico, legs, 6 y 137; y AHN, Consejos, leg. 16989.

12 Las que se conservan en Simancas ofrecen las rentas por trienios, mientras que las de Madrid lo hacen por quinquenios.
} 
novena pregunta del segundo interrogatorio, "si saben el verdadero valor de las rentas de dicho obispado, cuánto montan en cada año, en qué consisten y si tienen reservada alguna pensión". La respuesta de los testigos, aunque con frecuencia es meramente convencional, pues unos afirman no conocer la diócesis y otros remiten a las relaciones de valores de la secretaría del real patronato, se aproxima bastante a las cifras que ofrecen las valoraciones del real patronato y algunas aportan detalles interesantes. Los datos que se encuentran en las actas del consistorio suelen repetir las cifras de los procesos consistoriales y además indican el importe de la pensión cargada sobre la mitra.

\section{La carrera episcopal.}

La similitud de origen y formación presta a este grupo una notable homogeneidad, patente en las biografías de los prelados, que aparecen calcadas por un mismo patrón. Los provenientes del clero secular, después de estudiar gramática en su villa o ciudad natal, acuden a la universidad y obtienen una beca en un colegio. Si se trata de uno de los colegios mayores su suerte está asegurada, pues su poder era indiscutible. Del colegio muchos pasan al disfrute de alguna prebenda en los cabildos colegiales o catedrales y otros buscan acomodo en la burocracia civil (oidores, fiscales, etc.) o eclesiástica (provisor y vicario general, visitador, etc.) para dar el salto después a una mitra. Los que proceden del clero regular comportan aTgunas diferencias, aunque por lo general los electos son seleccionados entre los que han cursado estudios superiores en la universidad o en los centros de sus religión, han ejercido la docencia, han desempeñado cargos de gobierno en su religión o han asistido a los miembros de la familia real en tareas espirituales o culturales.

La carrera episcopal, por tanto, constituía un auténtico cursus honorum, en el que se ingresaba generalmente por una diócesis pobre y se ascendía por antiguiedad y méritos a las mitras más ricas y prestigiosas. Sólo personas de la familia real, de la primera nobleza o excepcionales comenzaban por una de las primeras mitras. De esta forma, la esperanza de ascenso era uno de los motivos de más peso para tratar de mantenerse en la gracia de la corona, pues los monarcas, a pesar de tener en cuenta los aspectos espirituales, no por eso dejaron de valorar los aspectos económicos anejos a la designación o traslado de los titulares de las mitras, manejando los nombramientos como instrumentos de su política estatal. 


\subsection{Criterios de selección.}

Desde que el papa Adriano VI concedió a Carlos I en 1523 el derecho de presentación de personas idóneas a las iglesias de los reinos de las coronas de Castilla y Aragón, los monarcas españoles obtuvieron el control de las personas que iban a ser pastores y señores de los obispados, premiándoles con el traslado a mitras más rentables, económicamente hablando, si su actuación se ajustaba a los dictámenes de la corona, o dejándoles transcurrir sus días en la sede que ocupaban.

La provisión del obispado de Cádiz discurrió en líneas generales por los cauces que marcó Felipe $\mathrm{II}^{13}$, si bien es verdad que la tendencia a considerar al obispo como un agente gubernamental del que se esperaba que fuese un celoso pastor y también un auxiliar político que exhortara al pueblo a la obediencia se fue reforzando progresivamente y determinó que el factor político, entendido en un sentido muy general aparezca como un componente esencial en los nombramientos a medida que avanzan los tiempos modernos ${ }^{14}$.

La provisión tenía que recorrer un largo camino diplomático hasta hacerse efectiva. Designada la persona por el monarca, se entablaba un proceso informativo sobre las cualidades y capacidades del electo, y sobre el status ecclesiae, es decir, sobre la situación de la catedral, de la ciudad episcopal y de la diócesis. Acto seguido, se expedía al embajador en Roma un documento de presentación de la persona designada para ese obispado ${ }^{15}$ con el fin de elevar la presentación a la curia romana, donde era examinada por el consistorio de cardenales. Aceptada la provisión, el electo o su representante abanaba las tasas debidas y la curia expedía las bulas, que al obispo de Cádiz le costaban 18.586 reales de vellón ${ }^{16}$. Estas se remitían a la corte de Madrid y desde allí al interesado. Cumplinentados los requisitos cortesanos por el electo, se libraban las cartas ejecutoriales para que las bulas tuvieran efecto y el nuevo obispo pudiera tomar posesión de la sede y entrar en posesión de las rentas de la mitra.

\footnotetext{
${ }^{13}$ Instrucción que debe observar la Cómara en las consultas para la provisión de prelacias (...), de 6 de enero de 1588, que pasó a integrar la ley 11, tít. 17, libro I de la Novisima Recopilación.

${ }^{14}$ La constatación de este hecho hace exclamara al nuncio Tiberi en 1829 que en España se considera a los prelados funcionarios públicos y se les traslada a una mitra con mayor renta como recompensa. Cfr, ASV, Segr. Stato, Ep. Moderna, 249 (1827-29), 466: Tiberi a Albani. Madrid 24 diciembre 1829. ${ }^{15}$ Esta documentación se conserva en el AEESS.

If La tasa nominal de las bulas de provisión se computaba en florines, pero la tasa real se pagaba en escudos de oro de Roma, de 15 julios cada uno. Su importe puede verse en BEESS, ms. 368, f. 233. La tasa nominal del obispado de Cádiz era de 250 tlorines, pero la tasa real se elevaba a 660 escudos de oro.
} 


\subsection{La edad de nombramiento.}

El examen de la edad media a que son nombrados los veintiséis obispos que rigen la diócesis de Cádiz entre 1564 y 1833 muestra un rasgo a la vez normal e indicativo del tipo de cuerpo social al que hacemos referencia. Los seleccionados son hombres en plena madurez vital, "venerables ancianos" para la concepción de la época. Los 55 años y algo más de cuatro meses que se registra como media general del periodo que se analiza no deja lugar a dudas respecto a las condiciones de madurez y responsabilidad que se exige a los que ocupan la sede episcopal. Esta afirmación se revalúa aún más si se tienen en cuenta los juicios que las gentes de aquella época emiten sobre la concepción habitual respecto a la vejez, ya que para ellos "llegar a los 52 años era raro y le colocaba uno en la venerable categoría de los ancianos"17. Es más, en la segunda mitad del siglo XVIII no se debía tener un criterio muy distinto cuando en la división por edades de la población censada situaban en el último tramo de la pirámide a todos los "de cincuenta años arriba"18. Los datos del cuadro primero muestran que la edad indicada experimenta un nivel de fluctuación relativamente importante a lo largo del periodo, pues los 56 años y dos meses de 1556-1699 bajan a 53 años y nueve meses en 1700-1833.

Cuadro 1. Edad media de preconización.

\begin{tabular}{ccccc}
\hline Periodo & Años & Meses & Días & Índice \\
\hline $1556-1699$ & 56 & 2 & 28 & 101,6 \\
$1700-1833$ & 53 & 9 & 15 & 97,1 \\
Media & 55 & 4 & 19 & 100,0 \\
\hline
\end{tabular}

También hay que precisar que, aunque la edad media se fija en 55 años y cuatro meses, la dispersión de edades es relativamente grande, pues seis son nombrados con menos de cincuenta, once con los cincuenta cumplidos, seis con más de sesenta y los tres restantes superan los setenta.

Por último, se ha de tener en cuenta que la fecha indicada es la de su primera preconización, pues hay seis obispos que llegan a Cádiz despućs de haber regido las diócesis de Almería (Alfonso Pérez, 1663, y Antonio Ibarra, 1680), Canarias (Juan Bautista Servera, 1777, y Antonio Martínez, 1790), Ceuta (Tomás

1" PEREZ MOREDA, V., Las crisis de mortalidad en la Esyaña Interior. Siglos XVI-XLX, Madrid, 1980, p. 188.

${ }^{18}$ Así se puede constatar en los censos de Aranda (1768) y Floridablanca (1787). 
del Valle, 1731) y Guadix (Juan Dionisio Fernández Portocarrero, 1640), lo que hace que la edad media de nombramiento para la sede gaditana se eleve un año.

\subsection{El reclutamiento regional.}

El estudio de la procedencia geográfica de los obispos que rigen la diócesis de Cádiz pone de manifiesto, al igual que sucede en otros obispados de la corona de Castilla, el predominio absoluto de los castellanos y, dentro de ellos, la supremacía de los naturales de la Castilla interior $(53,8 \%)$, seguidos a gran distancia por los andaluces $(26,9 \%)$ y los de la cornisa cantábrica y Navarra $(15,4 \%)$. La corona de Aragón sólo está representada por un valenciano, Juan Bautista Servera, que rige la diócesis de 1777 a 1782 , en que muere.

Como era de esperar, el análisis de la procedencia urbana o rural de estos prelados pone de manifiesto la primacía de los segundos $(53,8 \%)$ frente a los primeros $(46,2 \%)$.

\subsection{Un mundo social diverso.}

El examen de la extracción social de los elevados a prelacías aparece dificultado por la escasa información que aportan las fuentes consultadas. En los procesos informativos que se hacían cuando uno era nombrado obispo sólo la tercera pregunta del primer interrogatorio inquiere sobre los padres del candidato: "si es hijo de legítimo matrimonio, de honestos y católicos padres, y cómo se llaman", sin que demande información sobre su procedencia social. Esto da lugar a que únicamente en los casos de alta nobleza los testigos informen con ciertá precisión sobre el particular. Este es el caso de García de Haro (1564-1587), hijo de los marqueses de Carpio; Antonio Zapata (1587-1596), primogénito de Francisco Zapata, conde de Barajas y presidente del consejo de Castilla, que renunció a sus derechos de primogenitura a favor de su hermano; Maximiliano de Austria (15961602), hijo natural del archiduque Leopoldo de Austria; Plácido Pacheco (16231633), hijo natural de don Juan Pacheco, hermano del marqués de Carpio; Juan Dionisio Fernández Portocarrero (1640-1641), "hijosdalgos notorios, de casa y solar conocido, y como tales son señores de la casa de Palma, que está en Andalucía", entre otros. En caso contrario, se limitan a decir que son personas nobles y principales hidalgos (Guerra y Quesada), familias ilustres de la villa de Madrid y arzobispado de Toledo (del Valle), familias muy distinguidas (Utrera), o simplemente informan que son honestos y católicos. Algo similar ocurre con los 
episcopologios y biografías, pues sólo cuando pertenecen a los estratos más altos o más bajos de la sociedad, con mayor frecuencia hacia los títulos nobiliarios, dan información abundante.

La parquedad de datos que ofrecen las fuentes consultadas me ha llevado a simplificar la categoría social de los obispos gaditanos en cuatro grupos. La mayoría son miembros de la mediana y pequeña nobleza, tan abundante en el norte y centro de Castilla (46,2\%), otro porcentaje importante está constituido por miembros de la alta nobleza $(19,2 \%)$ y otro mayor por miembros de las clases medias, tanto hijos de labradores acomodados como de la burguesía y de las profesiones liberales $(30,7 \%)$. Sólo he encontrado un prelado de origen humilde, Lorenzo Armengual, hijo de pescadores del barrio del Perchel de Málaga.

\subsection{Niveles de instrucción.}

El análisis de la formación cultural de los prelados pone de manifiesto que todos, menos uno, son letrados; es decir, han cursado estudios superiores y poseen un grado académico. Diecinueve lo hacen en alguna de las universidades castellanas (seis en Salamanca, tres en Alcalá, dos en Compostela y Valladolid, y el resto en las de Granada, Irache y Sigüenza), uno se gradúa en la de Nápoles y cinco religiosos en centros de su religión. Sólo uno, el fraile franciscano Francisco Guerra, no está graduado porque "en la religión de san Francisco no hay grados de doctor ni maestro ni otros"19. La mayoría de ellos $(38,5 \%)$ obtiene el título de licenciado, mientras que el porcentaje de los doctores baja al 34,6 por 100 y el de los maestros al 23,1. Los datos del cuadro segundo indican el grado académico que poseen y la disciplina en que están graduados, observándose un predominio absoluto de la teología (60\%) sobre el derecho (40\%).

Cuadro 2. Grados y disciplinas que estudian.

\begin{tabular}{cccc}
\hline Grados & Teología & Derecho & Total \\
\hline Doctor & 4 & 5 & 9 \\
Licenciado & 5 & 5 & 10 \\
Maestro & 6 & - & 6 \\
Ninguno & - & - & 1 \\
Total & 15 & 10 & 26 \\
\hline
\end{tabular}

${ }^{19}$ ASV, Arch. Concist., PC, vol. 40, f. 391 
El estar graduado en alguna facultad calificaba a los provistos para "tener la doctrina que se requiere a un obispo para poderlo ser y enseñar a sus diocesanos". De ahí el interés de los testigos que intervienen en el proceso informativo en dejar bien claro que el electo, aunque no tienc grados, pose suficiente doctrina, como se declara en el proceso de Francisco Guerra en 1642.

\subsection{El cursus anterior.}

Otro indicador de la sociografia episcopal son los cargos o experiencia profesional anterior a la promoción al episcopado. El análisis de los cargos previos de los obispos de Cádiz pone de manifiesto que los canales que confluyen en la elección provienen de fuentes muy diversas, que se pueden englobar en los apartados siguientes:

- Asistencia a miembros de la familia real $\quad 2$

- Burocracia eclesiástica 7

- Clero capitular: dignidades y canónigos 6

- Clero parroquial: párroco de Madrid 1

- Inquisición: inquisidores y consejeros 4

- Ordenes religiosas: cargos de gobierno 6

Total

La frialdad de los datos anteriores requiere una explicación para su interpretación. La mayor parte de los miembros del clero secular que ocupan la sede gaditana están enclavados de una u otra forma en el clero capitular. Exactamente la mitad de los electos posee una prebenda capitular en el momento de su primera preconización y el 23 por 100 sólo tiene la prebenda cuando es nombrado. Entre los capitulares a los que se abren las puertas del obispado encontramos un archimandrita de Mesina y un abad de la colegiata de Alcalá la Real, dos dignidades de arcediano y prior, y dos canónigos. La burocracia eclesiástica aporta siete miembros: tres son provisores y vicarios generales, uno auditor de la rota romana y otros tres obispos auxiliares: Lorenzo de Armengual, nombrado auxiliar de Zaragoza en 1701, pasa a residencial de Cádiz en 1715²0 Juan Acisclo Vera y

\footnotetext{
"En 1705 Felipe V lo llama a la corte para que se encargue del gobiemo del consejo de Hacienda, en 1707 usume también el cargo de consejero de Castilla y en 1714, con la reforma de la administración central, se hace cargo de una de las secretarías del Despacho Universal. Al año siguiente deja los encargos de la corte y el monarca le nombra obispo de Cádiz y le honra con el titulo de marqués de Campo Alegre. Preconizado por la curia romana el 6 de mayo de 1715 , rige la diócesis hasta 1730 en que muere.
} 
Delgado, designado coadministrador de Sevilla en 1801, promueve a Cádiz en 1815; y Domingo de Silos, auxiliar de Caracas desde 1818, viene a Cádiz en 1825. En el curriculum de cuatro obispos gaditanos figura el desempeño de algún cargo inquisitorial en el momento de su nombramiento: tres son consejeros de la Suprema y otro inquisidor del tribunal de Toledo, La asistencia espiritual a la familia real está representada por un capellán y un confesor de la reina de Francia, María Teresa de Austria. El clero parroquial sólo cuenta con un miembro: Antonio Ibarra, párroco de San Ginés de Madrid, que en 1675 fue nombrado obispo de Almería y en 1680 promovió a Cádiz. Por último, los miembros del clero regular que acceden al obispado de Cádiz son nueve (el 34,6\% de los electos), pero sólo seis ocupan cargos de gobierno en sus religiones en el momento del nombramiento, los otros tres están inclusos en los apartados anteriores.

\subsection{Una larga vida.}

Operando con las fechas de nacimiento y defunción se puede conocer la vida media de los obispos que rigen la sede gaditana. En el periodo estudiado la media de vida se sitúa en 71 años y medio. Ahora bien, si se analiza la fecha obituaria de los distintos prelados se observa la amplitud real del abanico de decesos: dos mueren antes de cumplir los sesenta años, ocho entre sesenta y setenta, doce superan los setenta y cuatro los ochenta.

Con los datos anteriores se puede afirmar qué la esperanza de vida de los obispos de Cádiz es más alta que la de otros grupos sociales de la diócesis? Para contestar a esta pregunta tendría que disponer de monografías que estudiasen la mortalidad diferencial de los distintos grupos sociales, pero este tipo de estudios sigue siendo escaso y esto hace difícil valorar el comportamiento socialmente diferenciado de este grupo privilegiado, que al concentrar en sus manos un importante contingente del excedente agrario de la diócesis se vio a salvo de las crisis de mortandad provocadas por la falta de subsistencias y poco afectado por las crisis epidémicas que sufre la sociedad gaditana. Lo cierto es que la fecha obituaria de los prelados gaditanos es la más alta de Andalucía y de la mayor parte de las diócesis españolas ${ }^{21}$

\footnotetext{
${ }^{21}$ Información sobre la edad media a que mueren los obispos de las diferentes regiones españolas en BARRIO GOZALO, M., Los obispos de Castilla y León..., pp. 96-98.
} 


\section{La carrera del obispo en Cádiz.}

Económicamente hablando, la mitra de Cádiz estaba considerada como una de las medianas de la monarquía. Sus rentas experimentan un incremento relativo a lo largo del periodo estudiado, dando lugar a que del puesto 29 que ocupa en el ranking de los niveles de renta del conjunto de las mitras españolas en el periodo 1556-1699, baje al 25 en el de 1700-1833. El hecho económico, al combinarse con el político, determina los cambios que se operan a lo largo del periodo en lo referente a que los obispos de Cádiz sean nombrados de primera provisión o vengan trasladados de otras diócesis. De esta manera, mientras que en el periodo 1556-1699 los nombrados de primera provisión suman el 82,4 por 100, en 17001833 sólo representan el 66,7 por 100 . Este fenómeno da lugar a que entre la edad de primera preconización, que antes se indico, y la de nombramiento para la sede gaditana haya una diferencia de un año.

\subsection{El pontificado en Cádiz y su término.}

La duración de la carrera episcopal completa de los prelados que en algún momento rigen la diócesis gaditana se sitúa en algo menos de quince años, pero si sólo se contabilizan los años que rigen la diócesis de Cádiz el promedio desciende a 10 años y poco menos de dos meses, lo que equivale a decir que sólo invierten el 67,8 por 100 de su vida de obispos residenciales en la sede gaditana, mientras que el 32,2 por 100 restante lo emplean en el gobierno de otras iglesias de la monarquía. El cuadro tercero muestra que este porcentaje fluctúa a lo largo del periodo estudiado, aunque es en los años 1556-1699 cuando alcanza su nivel más bajo, al situarse en torno al 62 por 100 , frente al 73 por 100 que supone en los años 1700-1833.

Cuadro 3. Duración de los pontificados.

\begin{tabular}{|c|c|c|c|c|c|c|c|}
\hline & \multicolumn{3}{|c|}{$\begin{array}{l}\text { Periodo Duración total } \\
\text { Años Meses Días }\end{array}$} & \multicolumn{4}{|c|}{ En Cádiz } \\
\hline $1556-1699$ & 13 & 1 & 13 & 8 & 2 & 6 & 62,3 \\
\hline $1700-1833$ & 18 & 5 & 11 & 13 & 10 & 21 & 75,3 \\
\hline Media & 14 & 11 & 20 & 10 & 1 & 25 & 67,8 \\
\hline
\end{tabular}

El nombramiento para la mitra gaditana no significaba forzosamente el final de la carrera episcopal. Algunos (30,8\%) promueven a sedes más importantes y ricas, pero la mayoría $(69,2 \%)$ muere pastoreando la diócesis de Cádiz. 
El posible ascenso para un obispo de Cádiz consistía en el traslado a otra sede de mayor categoría, sobre todo en lo referente a los niveles de renta. $\mathrm{Y}$ efectivamente, en el caso de Cádiz, los ochos traslados implican una promoción porque pasan a ocupar otras sedes con mayores rentas, según se puede apreciar en los datos que se ofrecen a continuación:

\begin{tabular}{c|cc|cc|c}
\hline \multirow{2}{*}{ Obispo } & \multicolumn{2}{|c|}{ Cádiz } & \multicolumn{2}{c|}{ Traslado } & Diferencia \\
& Años & Renta & Sede & Renta & en\% \\
\hline García de Haro & $1564-1587$ & 11.000 & Málaga & 35.000 & +218 \\
A. Zapata & $1587-1596$ & 12.500 & Pamplona & 22.000 & +76 \\
M. de Austria & $1596-1601$ & 10.500 & Segovia & 25.000 & +138 \\
P. Pacheco & $1623-1633$ & 12.000 & Plasencia & 40.000 & +233 \\
F. Guerra & $1642-1656$ & 16.000 & Plasencia & 32.000 & +100 \\
D. Castrillo & $1673-1676$ & 18.000 & Zaragoza & 40.000 & +122 \\
J. de Isla & $1677-1680$ & 18.000 & Burgos & 40.000 & +122 \\
F. Cienfuegos & $1819-1824$ & 25.000 & Sevilla & 200.000 & +700 \\
\hline
\end{tabular}

Sin embargo, más de dos tercios de los obispos de Cádiz $(69,2 \%)$ terminan la carrera episcopal en la sede gaditana y mueren en el desempeño de su cargo.

\section{Aspectos económicos.}

Aunque resulta difícil evaluar con cierta exactitud la riqueza que posee la iglesia gaditana, los siguientes datos pueden servir de orientación. El Estado de cuentas que los procuradores de la Congregación del clero de los reinos de Castilla y León presentan en Roma en 1630 informa que el importe de las rentas eclesiásticas del obispado de Cádiz representan el 8 por 100 de la renta global de la diócesis. Este elevado volumen de riqueza se distribuye de forma desigual entre los distintos beneficiarios, siendo el obispo quien relativamente se apropia de la porción más elevada, pues se beneficia del 10 por 100 de las rentas eclesiásticas seculares de la diócesis ${ }^{22}$. A finales del siglo XVIII la participación del prelado

${ }^{22}$ ASV, Misc. Arm. I, vol. 90, f. 246: Valor de todas las rentas eclesiásticas y seglares de los reinos de Castilla y León, reducidos los frutos de la tierra a dinero, y en particular se declara el de los cinco arzobispados y 31 obispados (...). Año 1630. 
apenas varía, pues en 1799 supone el 10,3 por 100 del importe de las rentas eclesiásticas del obispado ${ }^{23}$.

Los titulares de la mitra gaditana se encuentran, por tanto, entre las personas que tienen una elevada participación en el excedente numerario de la diócesis, aunque para la justa valoración de las rentas episcopales hay que tener en cuenta los gastos y cargas que pesan sobre ellas, así como su contribución a la cultura y a la asistencia social, tanto a través de la limosna como creando y protegiendo instituciones benéfico-asistenciales en la diócesis.

\subsection{Naturaleza de las rentas.}

Las fuentes consultadas permiten afirmar que las rentas de la mitra provienen en partes muy desiguales de los ingresos que producen las propiedades rústicas que posee, los diezmos que percibe y las rentas de carácter vario que detenta, que son "de poca consideración".

Las propiedades rústicas están constituidas por las 597 aranzadas de tierra que tiene en el término de Jerez, distribuidas en cinco hazas de extensión desigual. Explotadas en régimen de arrendamiento, el importe de la renta, que en algunos momentos del último tercio del siglo XVl se paga en especie de trigo, en el XVIII se abona normalmente en dinero. Tenía también una huerta en la villa de Vejer, conocida con el nombre de huerta de san Ambrosio y otra extramuros de Cádiz, que compró el obispo Servera en 1780. La cuantía de los ingresos que aportan estas propiedades, a pesar de su importancia, sólo constituyen una pequeña parte de las rentas de la mitra, que apenas suponen el 4 por $100^{24}$.

El capítulo mayoritario de las rentas de la mitra (en torno al 95 por 100) está constituido por frutos decimales de diferentes especies, que se agrupan en las cuentas en dos apartados: el diezmo del trigo y cebada, que se cobra en especie y se distribuye entre los interesados en su misma especie, y las "matrículas de maravedíes", que incluyen los restantes productos decimales. Estos se arriendan en pública subasta y se reparten en dinero. La porción que el obispo percibe en los diezmos de la diócesis es bastante elevada, pues se acerca al 15 por 100 del total de los frutos decimales recolectados. Según la relación de los diezmos de

\footnotetext{
"MORGADO GARCIA, A., Iglesia y sociedad..., p. 248.

${ }^{34}$ El año 1715 el mayordomo del obispo de Cádiz envía a la Cámara un informe detallado de las propledades que tiene el prelado y el importe de su renta. Cfr. AHN, Consejos, leg. 16989.
} 
granos del obispado que el prelado envía a la cámara de Castilla para el periodo 1756-1773, corresponde a la mitra el 14,4 por 100 de los mismos ${ }^{25}$.

La mayor parte de la rentas decimales son de carácter cerealístico, con un predominio absoluto del trigo, cuyo importe supone casi la mitad de los ingresos de la mitra, frente a la cebada que apenas llega al 5 por 100 y desde mediados del setecientos va perdiendo importancia. A poca distancia del trigo sigue el importe de los diezmos que se cobran en dinero (ganados, vino, hortalizas, etc.), cuya representación se sitúa en torno al 40 por 100 . La importancia de cada uno de estos conceptos varía de acuerdo con la fluctuación de las cosechas y del precio a que se valora cada uno de los productos. La muestra del cuadro siguiente especifica la fluctuación de los diferentes conceptos y resalta la estabilidad del trigo hasta el siglo XVIII, en que experimente una importa subida, comenzando a descender después de la guerra de la Independencia. La cebada incrementa su parti cipación en el siglo XVII, pero en XVIII invierte la tendencia y disminuye progresivamente. Los diezmos cobrados en dinero o menudos permanecen bastante estables hasta el siglo XVIII en que bajan ligeramente, recuperándose en los primeros años del $\mathrm{XIX}^{26}$.

Cuadro 4. Fluctuación de los componentes de las rentas decimales (\% de la renta total).

\begin{tabular}{lcccccc}
\hline Concepto & $\mathbf{1 5 7 5 - 7 9}$ & $\mathbf{1 6 3 4 - 3 8}$ & $\mathbf{1 6 8 6 - 9 0}$ & $\mathbf{1 7 2 4 - 2 8}$ & $\mathbf{1 7 7 6 - 8 0}$ & $\mathbf{1 8 1 5 - 1 9}$ \\
\hline Trigo & 47,8 & 47,0 & 48,5 & 54,9 & 59,5 & 52,9 \\
Cebada & 5,1 & 7,2 & 6,8 & 5,4 & 3,0 & 1,9 \\
Menudos & 39,2 & 41,2 & 40,6 & 36,2 & 34,5 & 41,9 \\
Total & 92,1 & 95,4 & 95,9 & 96,5 & 97,0 & 96,7 \\
\hline
\end{tabular}

Los diezmos de granos, capítulo mayoritario de las rentas decimales, se pueden evaluar de forma aproximativa en una cantidad media anual de 4.922 fanegas de trigo y 1.040 de cebada, aunque su índice de fluctuación se acerca al 50 por

2.5 Este porcentaje ha sido deducido de los datos que aparecen en la Relación de diezmos de trigo y cebada del obispado de Cádiz de los años 1756 hasta 1773 (AHN, Consejos, leg. 4181), y las Relaciones de valores de la mitra (Ibidem, leg. 16989). ANTÓN SOLE, P., La iglesia gaditana en el siglo XVII, pp. 101-102, indica que en la sacristía baja de la catedral se encuentra una tabla con la Práctica de repartirse las rentas decimales de pan y maravedies de este obispado de Cádiz, pero no describe cómo se hacía y la parte que correspondía a cada partícipe en los diezmos. Más información en TRAVERSO, F., Los diezmos en el obispado de Cádiz. Percepción, distribución y evolución (15911648), Cádiz 1987.

${ }^{26}$ Los datos se han tomado de AGS, Patronato Eclesiástico, leg. 137, y AHN, Consejos, leg. 16989. 
100 y en el caso de la cebada supera el cien por cien, según se indica en el cuadro quinto. En el caso del trigo los índices más bajos se dan en los últimos años del siglo XVI (a partir de 1586-87) y se mantienen por debajo de la media hasta la década de 1720 , en que inician un largo periodo de expansión que se prolonga hasta los primeros años del siglo XIX. El comportamiento de la cebada es diferente y, excepto la caida de los últimos años del XVI, en el XVII se recupera y se mantiene a un nivel alto hasta XVIII, en que experimenta un descenso progresivo, con alguna excepción, hasta el XIX, en que cae bruscamente ${ }^{27}$.

Cuadro 5. Diezmos de granos percibidos por el obispo $(100=$ media de todo el periodo).

\begin{tabular}{cccc}
\hline Años & Trigo & Cebada & Total \\
\hline $1555-1574$ & 106,0 & 136,5 & 111,3 \\
$1575-1599$ & 83,2 & 92,0 & 84,7 \\
$1600-1624$ & 86,6 & 116,8 & 91,9 \\
$1625-1649$ & 98,5 & 131,4 & 104,2 \\
$1650-1674$ & 90,4 & 133,7 & 97,9 \\
$1675-1699$ & 95,1 & 112,0 & 98,0 \\
$1700-1724$ & 78,8 & 73,4 & 77,8 \\
$1725-1749$ & 119,7 & 105,5 & 117,3 \\
$1750-1774$ & 122,5 & 84,8 & 116,0 \\
$1775-1800$ & 141,1 & 83,2 & 131,0 \\
$1800-1824$ & 78,2 & 34,0 & 69,9 \\
\hline
\end{tabular}

Por último, están las rentas de carácter vario, que apenas representan el uno por ciento de los ingresos de la mitra y están constituidas por la "renta que llaman del extremeño de Jerez de la Frontera", que produce anualmente cincuenta carneros y algunos maravedies; los censos y tributos situados en Medina, Gibraltar y Tarifa, que rentan 586 reales de vellón al año, y el "juro viejo sobre las aduanas de Sevilla", que reditúa otros 706 reales, pero que en el siglo XVIII ya no se paga.

\footnotetext{
27 Se han utilizado datos de AGS, Patronato Eclesiástico, legs. 6 y 137, y AHN, Consejos, leg. 16989, completados para algunos años đel siglo XVIII con los que ofrece MORGADO GARCIA, A., Iglesia y sociedad..., pp. 252-254.
} 
4.2. De la renta bruta a la renta disponible por el obispo.

Descrita la naturaleza de las rentas, paso a ofrecer una evaluación global de su importe, advirtiendo antes que los ingresos de la mitra, al provenir en su casi totalidad de rentas de carácter decimal, están sujetos a la fluctuación de las cosechas y de los precios, de tal manera que la conjunción de estas dos variables determina el movimiento de las rentas. De todas formas, hay que precisar que en la diócesis de Cádiz, a pesar de que el 15 de octubre de 1600 la tasa del trigo se elevó a dieciocho reales la fanega de trigo y a nueve la de cebada, los granos se continuaron valorando de acuerdo con la real provisión de 22 de septiembre de 1582, que fijaba el precio de la fanega de trigo en catorce reales y en seis la de cebada. Esta forma de valoración continuó utilizándose hasta la segunda mitad del siglo XVIII, en que se comienzan a valorar al precio de venta ${ }^{28}$. En suma, la cuantía de las rentas de la mitra está determinada por la incidencia de las cosechas y de los precios, y desde finales del setecientos también por la mala forma de diezmar, que se acentúa sobremanera a partir de las Cortes de Cádiz, sin que los obispos ni el gobierno puedan poner remedio ${ }^{29}$.

La documentación utilizada permite afirmar que la renta bruta de la mitra se mueve entre los 138.686 reales de vellón, que por término medio importa al año en la segunda mitad del siglo XVI, y los 443.417 que suma en la segunda parte del XVIII, experimentando un importante descenso en el primer tercio del XIX (ver cuadro 6).

Para evaluar la renta líquida y pensionable de la mitra hay que descontar los gastos y cargas provenientes de la administración de las rentas ${ }^{30}$ y lo que le corresponde pagar por la contribución del subsidio y excusado, que a mediados del siglo XVII suma 17.443 reales de vellón. Esta cantidad apenas varía hasta la segunda mitad del XVIII en que los gastos de administración se duplican amplia-

\footnotetext{
${ }^{23}$ AHN, Consejos, leg. 17002. Esta forma de valorar los granos también se observa en otras diócesis de Andalucia occidental.

${ }^{20}$ Las medidas adoptadas en relación con los diezmos por el gobierno de José I y las Cortes de Cádiz influyeron de forma decisiva en que los dezmeros perdiesen sus escrúpulos y se resistieran al pago de los diezmos, sobre todo después del decreto del 29 de junio de 1821 , que redujo a la mitad el pago de todos los diezmos y primicias. Restablecida la obligatoriedad del pago íntegro, aumentó el clamor del estado eclesiástico ante el poco rigor con que se efectuaba. Sin embargo, ya antes del Trienio se había planteado el problema del pago de los diezmos. La real orden de 8 de noviembre de 1817 establecía que los diezmos se pagasen "con exactitud y religiosidad". Años después, en la circular de 14 de diciembre de 1826 aparece claramente señalada la falta de rigor en el pago de los diezmos y se indica que la defraudación era, a la sazón, "escandalosa por el efecto de la desmoralización general de los pueblos, producida por la libertad y desenfreno con que en las últimas épocas de revolución se habían difundido doctrinas erróneas y contrarias a la iglesia y el trono".

${ }^{30}$ Los diezmos del acervo común se administran por la contaduría decimal, a cargo del cabildo catedral, al que había que abonar una cantidad por los costes.
} 
mente, disparándose aún más después de la guerra de la Independencia. Por ejemplo, en el quinquenio 1815-1819 el importe anual de los gastos suma 105.303 reales, distribuidos de la siguiente forma: 43.892 por la recolección de los granos, 40.872 por la administración, a razón del 10 por 100, y 20.539 en concepto de subsidio ordinario y extraordinario". De esta forma, el importe de estos gastos que, hasta mediados del siglo XVIII sólo representa el 8,5 por 100 de la renta bruta, sube al 9,1 en la segunda mitad y se dispara hasta el 21,2 por 100 en el primer tercio del siglo XIX, al incrementarse considerablemente los gastos de administración y los subsidios extraordinarios. Descontado el importe de los gastos y cargas fijas, tenemos la renta líquida, que experimenta una evolución similar a la bruta hasta principios del siglo XIX, en que muestra una caida más fuerte (ver cuadro 6).

Estas cifras son muy similares a las que ofrecen los procesos informativos del Archivo Vaticano, aunque se observan algunas diferencias. Hasta mediados del siglo XVIII los valores vaticanos son ligeramente superiores, pero en la segunda mitad del setecientos son un 34 por 100 más bajos y en el primer tercio del XIX un 35 por 100 más altos ${ }^{32}$.

Una vez que se conoce la renta líquida y pensionable, se puede obtener el importe de las pensiones que gravan las rentas de la mitra, con el fin de conocer el volumen de renta que queda a la libre disposición del obispo, tanto para el gasto de su casa como para otros desembolsos que precise o guste hacer.

La curia romana admitía que el monarca, al hacer la presentación del nuevo obispo, pudiera reservarse hasta la tercera parte de la renta líquida. En teoría esta porción se asignaba por Roma a los cardenales que tenían escasas rentas y, en segundo lugar, a los sujetos que el monarca quería agraciar; pero en la práctica era el rey quien designaba a las personas que deseaba beneficiar y el papa se limitaba a extender las bulas con la autorización canónica para el disfrute de la pensión ${ }^{33}$.

\footnotetext{
"AHN, Consejos, leg. 16989: Relación de los valores de la mitra en el quinquenio 1815-1819.

${ }^{32}$ ASV, Arch. Concist., PC, vals. citados en la nota S. Las cifras que ofrece Morgado (Iglesia y sociedad..., pp. 252-254) sobre las rentas de la mitra en el siglo XV1II son sensiblemente más bajas, sobre todo para la segunda mitad de la centuria (160.840 reales de media anual en el periodo $1700-1749$ y 282.625 reales en el de 1750-1799), que las que registran las relaciones de valores de la secretaría del real patronato, que yo utilizo (ver cuadro 6 , columna cuarta), y las que se indican en los procesos consistoriales. La explicación se debe, a mi juicio, a que las valoraciones que se hacen para el reparto del subsidio (utilizadas por Morgado) siguen calculando los granos a un precio convencional a lo largo de todo el siglo, mientras que las relaciones de valores de la segunda mitad del setecientos lo hacen al precio de venta.

3: Estas bulas se encuentran en AHN, Consejos, legs. 16990 (bulas de las pensiones impuestas sobre las rentas de la mitra de Cádiz desde el año 1644 hasta 1803) y 16991 (bulas de los años 1804-1830).
} 
La secretaría del real patronato era quien marcaba las reglas sobre las pensiones, tanto en su imposición como en su distribución. Cuando moría el obispo o era trasladado a otra sede, la secretaría pedía a la iglesia gaditana relación de los valores de la mitra $y$, descontados los gastos y cargas fijas antes descritos, se deducía la tercera o cuarta parte, que era la cantidad que el monarca acostumbraba a reservar al hacer la presentación del nuevo obispo a Roma ${ }^{34}$.

Estas pensiones se cargaban o aumentaban al tiempo de hacer la presentación del nuevo obispo, de forma que la presentación y la notificación de la pensión reservada se hacía al mismo tiempo ${ }^{35}$. El nominado obispo, al aceptar la mitra, debía prestar también consentimiento a las pensiones impuestas, según se lee en la bula que la curia romana expedía al electo:

... proveemos la expresada iglesia de Cádiz en ti, Alfonso Vázquez, sobre cuya mesa episcopal y sus frutos, rentas y productos, hemos concedido en el día de hoy que se reserve una o más pensiones anuales hasta la cantidad de 3750 ducados de oro de cámara"3.

Aunque la curia romana autorizaba que las pensiones importasen hasta la tercera parte de la renta líquida, sin que ésta fuera rebasada, según se lee en las actas consistoriales:

Cum reservatione pensionum usque ad sumnam 2.921 ducati pro personis nominandis, dunmodo omnes in simul tertiam partem fructum non excedentant ${ }^{37}$,

la práctica seguida por la secretaría del real patronato en el obispado de Cádiz hasta finales del siglo XVIII fue la de cargar la pensión a razón de la cuarta parte de su valor líquido, "sin duda por lo corto que su valor fue en tiempos anteriores, aunque el provisto ha de otorgar el consentimiento del importe de la tercera parte para preservar la regalía de V. M." ${ }^{238}$. Los datos del cuadro sexto muestran que así se hace hasta el año 1801 , en que se impone al obispo electo, Francisco Javier

\footnotetext{
${ }^{14}$ Sobre las pensiones ver los trabajos de CLOULAS, I., "La monarquie catholique et les revénus episcopaux: Les pensiones sur les mitres de Castille pendant le régne de Philippe II", en Mélanges de la Casa de Velásquez, 4 (1968), pp. 107-142; FERNÁNDEZ, L., "Pensiones a favor de eclesiásticos extranjeros cargadas sobre las diócesis de la Corona de Castilla", en Hispania, 34 (1974), pp. 507-577; HERMANN, Ch., L'Eglise d'Espagne sous le patronage royal (1476-1834), Madrid 1988, pp. 165I 80; y BARRIO GOZALO, M., "Los obispos de Andalucía... ", pp. 158-168.

"Los despachos del rey a su embajador en Roma para que solicite las bulas de concesión de la pensión se guardan en el AEESS.

${ }^{36} \mathrm{AHN}$, Consejos, leg. 16989.

${ }^{17}$ ASV, Arch. Concist., AC, vol. 22, f. $141 \mathrm{r}$ : Pensiones impuestas a Diego Castrillo, nombrado Obispo de Cádiz en el consistorio de 29 de mayo de 1673.

${ }^{8} \mathrm{AHN}$, Consejos, leg. 16988: Cámara al rey. Madrid 5 junio 1790.
} 
Utrera, a razón de la tercera parte. En las dos provisiones siguientes los electos tienen que aceptar las pensiones impuestas, aunque superan con creces la tercera parte. Por ejemplo, según los valores de los años 1823-1826 la renta líquida de la mitra importa 146.340 reales de vellón y la tercera parte 48.780 , pero las pensiones con que se halla gravada suman 151.988 reales; es decir, más de lo que importa la renta. La explicación de este hecho que viola la normativa legal hay que buscarlo en los elevados ingresos que la mitra de Cádiz tiene en los últimos años del siglo XVIII y primeros del XIX, lo que motiva que la tercera parte correspondiente a las pensiones fuera también muy alta. $Y$ además, como en estos años la secretaría del real patronato tiende a imponer pensiones con carácter de perpetuidad a favor de instituciones benéfico-sociales la cuantía de las pensiones vivas se mantiene bastante estabilizada durante todo el periodo, mientras que las rentas de la mitra descienden considerablemente, y esto determina que la tercera parte de los años anteriores a la guerra de la Independencia suponga después de la contienda el 78 por 100 y en 1825 más del cien por cien. Ante esta situación, el titular de la mitra de Cádiz, al igual que hacen otros prelados, pide a la Cámara que le dispense de pagar el importe de las pensiones que exceda de la tercera parte, lo que consigue con la circular de 13 de julio de 1827 , en que se dispone que las pensiones que superen la tercera parte "se rebajen a prorrata entre los pensionistas". Sin embargo, las resoluciones de 1 de enero y 28 de diciembre de 1829 matizan la declaración anterior y precisan que las pensiones perpetuas impuestas a favor de la Orden de Carlos III y de instituciones benéficas no estaban sujetas a rebaja alguna ${ }^{39}$.

Cuadro 6. Las rentas de los obispos de Cádiz (Media anual en reales de vellón)

\begin{tabular}{cccccc}
\hline Periodo & R. Bruta & Cargas & R. Liquida & Pensiones & R. Disponible \\
\hline $1556-1599$ & 138.686 & 9.505 & 129.181 & 31.900 & 97.281 \\
$1600-1649$ & 144.321 & 11.305 & 133.016 & 30.766 & 102.250 \\
$1650-1699$ & 172.187 & 17.159 & 155.028 & 40.070 & 114.958 \\
$1700-1749$ & 190.396 & 16.618 & 173.778 & 38.371 & 135.407 \\
$1750-1799$ & 443.417 & 40.369 & 403.048 & 67.488 & 335.560 \\
$1800-1833$ & 282.408 & 59.748 & 222.660 & 116.371 & 106.289 \\
\hline
\end{tabular}

${ }^{30}$ Información sobre este problema en AHN, Consejos, leg. 16991. 
La distribución de estas pensiones quedaba en manos del monarca que las repartía, generalmente con carácter vitalicio, entre instituciones, personas particulares, miembros de la administración y del clero. En el siglo XVIII las instituciones benéficas acaparan la mayor parte de las pensiones que gravan las rentas de la mitra y en la provisión de 1801 el fenómeno se acentúa todavía más, de forma que en los años 1813-1827 la mayoría de las pensiones están asignadas a instituciones.

Si del importe de la renta líquida se descuentan las pensiones que están cargadas sobre la mitra se obtiene la renta disponible de la que podía usar libremente el obispo. Los datos de la última columna del cuadro sexto registran su importe y muestran que, a excepción de las últimas décadas del siglo XVIII, los obispos gaditanos disponen de poco más de cien mil reales de vellón al año, lo que explica que los prelados se lamenten algunas veces de la cortedad de las rentas, mermadas en los años 1809-1833 todavía más por el peso de las pensiones y la mala forma de diezmar, lo que impide a los obispos socorrer debidamente a los pobres y sostener las instituciones benéficas, según indica el contador de la mitra en 1815 .

Si el estado de la agricultura no mejora y también la escrupulosidad en la paga de los diezmos -dice el contador-, como el obispado de Cádiz está pensionado cerca de su mitad y estas pensiones se pusieron en tiempos muy felices y las rentas han decrecido y ellas son las mismas, no guardan proporción con el estado actual de sus rentas; a lo que se agrega que se ha aumentado considerablemente una multitud de pobres que antes no existían en esta plaza, y que no puede socorrer como a los demás con pequeñas limosnas, y un obispo que nada tenga que dar y que no pueda socorrer algunas necesidades siempre será mal visto y su ministerio mal recibido"t!.

El excedente numerario que cada año queda al prelado lo emplea fundamentalmente en sufragar los gastos que dimanan del abono de los salarios de los oficiales y dependientes de la administración episcopal, del gobierno de su casa, de las limosnas que hace y de otros muchos conceptos, como financiar instituciones benéficas y obras de arte o acumular riquezas.

Para llevar a cabo su misión pastoral y de gobierno el obispo se auxilia de unos colaboradores a los que abona un determinado salario. Su número, aunque varía de acuerdo con el talante de cada prelado, por lo general se reduce al provisor y vicario general, secretario de cámara, fiscal y cierto número de oficiales.

El gobierno y cuidado de la casa episcopal estaba a cargo del administrador o mayordomo, que debía llevar cuenta de todos los gastos, cuidar el vestuario,

40 AIIN, Consejos, leg. 16989: Contador del obispo a la Cámara Cádiz 20 septiembre 1815. 
velar de los servidores y criados, prever lo necesario para la alimentación y buena marcha de la casa y hacer los reparos que fuera menester en las casas y propiedades de la mitra.

Las limosnas repartidas por el obispo a pobres y necesitados absorben cada año, sobre todo en tiempos de carestía o epidemia, una parte importante de las rentas de la mitra. Con un poco de exageración León afirma que el obispo Tomás del Valle (1731-1776) invertía casi todas las rentas de la mitra en el socorro de los pobres, "resultando de las cuentas de administración que muchos años importaban más las limosnas que las rentas" 4 . A veces la actitud limosnera se torna previsora y se traduce en la fundación o consolidación de obras de tipo asistencial, religioso o cultural. Los obispos Guerra y Quesada prestan su ayuda al hospital de mujeres, Alonso Vázquez aporta dinero para levantar el edificio nuevo de la Casa cuna. Isla funda una casa de recogidas, Alonso de Talavera da grandes sumas para el hospital que los religiosos de San Juan de Dios tenían en la Isla de León. Armengual gasta más de quinientos mil reales en la construcción de la iglesia de San Lorenzo, como ayuda de parroquia en la ciudad. Tomás del Valle colabora económicamente en la nueva fábrica de los hospitales de mujeres y de la Santa Caridad y, sobre todo, en el de la Isla de León, que puso sobre el patronato de la mitra. Escalzo apoya y fomenta el establecimiento de Sociedades económicas y Martínez de la Plaza presta ayuda a los hospitales gaditanos, amplía el de Medina Sidonia, construyendo a sus expensas enfermerías para hombres y mujeres, y levanta otro en Los Barrios. Después de la guerra de la Independencia, el descenso de las rentas de la mitra impide a los obispos socorrer debidamente los establecimientos benéficos, que "se hallan en la mayor decadencia y es menester sostener para que no se complete su ruina", y de forma especial la Casa de expósitos, pues las limosnas y socorros con que se procura aliviar no son suficientes para sostenerla. ${ }^{42}$

Por último, no se deben olvidar los muchos gastos que los obispos deben hacer para satisfacer el importe de las bulas, la mesada eclesiástica y los que origina la consagración, el viaje a su iglesia y anueblar la casa episcopal. Esto explica que a la muerte de los prelados gaditanos el espolio no sea de gran cuantía en la mayoría de los casos ${ }^{43}$.

\footnotetext{
"ANTÓN SOLE, P., La Iglesia gaditana..., p. 168.

${ }^{42} \mathrm{AHN}$, Consejos, leg. 16989: Contador del obispo a la Cámara. Cádiz 20 septiembre 1815.

${ }^{43}$ MOR GADO GARCIA, A., Iglesia y sociedad..., pp. 80-81, ofrece algunos datos sobre el importe de los bienes muebles que se encuentran a la muerte de algunos obispos gaditanos del siglo xviii: 37.000 reales los de Tomás del Valle; 54.492 los de Armengual, 351.472 los de Servera y 34.346 los de Escalzo.
} 


\section{A modo de conclusión.}

En las páginas anteriores he presentado un esbozo de lo que podría ser la sociología de la jerarquía eclesiástica gaditana, pero habría que profundizar en cada uno de los aspectos que se apuntan y completar con el desarrollo de otros nuevos, como la vida material, las actitudes mentales, la vida social, cultural y religiosa, o el arte del bien vivir y bien morir. Estos aspectos, que se podrían analizar a través de los espolios y testamentos que Morgado utiliza en algún caso, nos permitiría entrar en contacto con la dimensión humana de este grupo privilegiado: su escenario cotidiano, estilo de vida, biblioteca y cultura, caridad o beneficencia, y también su sintonía o rechazo de las corrientes culturales dominantes.

En segundo lugar, el estudio más profundo y detallado de las rentas de la mitra permitiría conocer durante un periodo de larga duración la incidencia que las guerras, las malas cosechas y los agentes naturales ejercen en la evolución de las rentas episcopales, y también en qué medida contribuyen a financiar obras asistenciales y culturales en la diócesis. Las posibilidades son muchas y sugestivas, y la documentación no falta para llevar a cabo estudios que completen y enriquezcan las aportaciones que Antón Solé y Morgado García ofrecen de los prelados del setecientos, a fin de tener un mejor conocimiento de esta importante elite de poder gaditana. 